\title{
REVIEW ARTICLE OPEN Adiponectin signalling in bone homeostasis, with age and in disease
}

\author{
Jonathan W. Lewis ${ }^{1}$, James R. Edwards ${ }^{2}$, Amy J. Naylor ${ }^{1}$ and Helen M. McGettrick (1)
}

Adiponectin is the most abundant circulating adipokine and is primarily involved in glucose metabolism and insulin resistance. Within the bone, osteoblasts and osteoclasts express the adiponectin receptors, however, there are conflicting reports on the effects of adiponectin on bone formation and turnover. Many studies have shown a pro-osteogenic role for adiponectin in in vivo murine models and in vitro: with increased osteoblast differentiation and activity, alongside lower levels of osteoclastogenesis. However, human studies often demonstrate an inverse relationship between adiponectin concentration and bone activity. Moreover, the presence of multiple isoforms of adiponectin and multiple receptor subtypes has the potential to lead to more complex signalling and functional consequences. As such, we still do not fully understand the importance of the adiponectin signalling pathway in regulating bone homeostasis and repair in health, with age and in disease. In this review, we explore our current understanding of adiponectin bioactivity in the bone; the significance of its different isoforms; and how adiponectin biology is altered in disease. Ultimately, furthering our understanding of adiponectin regulation of bone biology is key to developing pharmacological and non-pharmacological (lifestyle) interventions that target adiponectin signalling to boost bone growth and repair in healthy ageing, following injury or in disease.

Bone Research (2021)9:1

; https://doi.org/10.1038/s41413-020-00122-0

The principal cellular constituents of bone (primarily osteoblasts and osteoclasts) rapidly respond to circulating signals, altering global levels of bone formation and resorption respectively, and thus impacting bone homeostasis. ${ }^{1-3}$ The effects of adiponectin in bone have been researched in multiple conditions; however, these studies report variable outcomes with little explanation. Further exploration of adiponectin signalling is essential to fully understand the possibility of promoting or inhibiting its actions during ageing or disease. Of note, very few studies have examined the effect of adiponectin on osteoclasts, so we understand much less about its role in bone turnover. Here we explore the current literature on adiponectin in bone, looking in depth at the comparison between human and murine in vivo and in vitro data in health, with age and in disease, with reference (where possible) to the adiponectin isoform described.

\section{ADIPONECTIN}

Adiponectin is the most abundant circulating adipocyte-secreted adipokine found in blood serum $(5-15 \mu \mathrm{g} / \mathrm{mL}) .{ }^{4,5}$ The full-length protein ( 244 amino acids ${ }^{6}$ ) can be cleaved into smaller active components, ${ }^{7}$ which circulate either as it's globular domain ${ }^{7}$ or as full-length homo-complexes referred to by their differing molecular weights (MW): a trimer (low MW; LMW); a hexamer (medium MW; MMW) or an oligomer (high MW; HMW) (Fig. 1). ${ }^{8-10}$ At a cellular level, adipocytes within the bone marrow adipose tissue (BMAT) and white adipose tissue (WAT) produce all of these adiponectin isoforms. ${ }^{11}$ For example, similar levels of adiponectin gene expression were observed in murine adipocytes isolated from WAT or BMAT. ${ }^{11}$ Yet protein expression was reportedly lower in rat total BMAT lysates ${ }^{12}$ and higher in adipocytes isolated from BMAT from rabbits and healthy 30 -year old humans, ${ }^{11}$ compared to WAT. As such adipocytes from both tissues can contribute to the local levels of adiponectin within the bone (and bone marrow), as well as the circulating levels of adiponectin that are more commonly reported in studies. Indeed, BMAT levels positively correlate with total serum adiponectin levels in humans. ${ }^{13}$ Whilst, the relative contribution of each adipose tissue to the levels of adiponectin in the bone is unclear, and may change with age and disease (as discussed in the later sections), many studies speculate that due to its proximity BMAT acts as the largest contributor of adiponectin to the local bone levels.

Adiponectin mediates its effects through adiponectin receptors 1 and 2 (AdipoR1 and AdipoR2) ${ }^{14,15}$ leading to downstream signalling through several pathways including AMP kinase (AMPK), $\mathrm{PI}$ KK/protein kinase $\mathrm{B}$, MAP kinase (MAPK), STAT3 (signalling transducer and activator of transcription 3) and ceramidase activation (Fig. 1). ${ }^{16-18}$ In addition to the classical adiponectin receptors, HMW and MMW adiponectin can also interact with Tcadherin (cadherin-13; CDH13). ${ }^{19,20}$ However, AdipoR1 and R2 knockout mice have a near-complete lack of adiponectin signalling, ${ }^{21}$ thus the functional relevance of T-cadherin in mediating the effects of adiponectin is currently unclear. Moreover, potential signalling mechanisms downstream of adiponectin-T-cadherin interactions have not yet been fully explored. Crucially, evidence suggests that the individual adiponectin receptors have differing binding efficacies for the different isoforms of adiponectin; with a murine myocyte cell line

\footnotetext{
${ }^{1}$ Rheumatology Research Group, Institute of Inflammation and Ageing, University of Birmingham, Birmingham B15 2T, UK and ${ }^{2}$ Ageing \& Regeneration Research Group, Botnar Research Centre, University of Oxford, Oxford OX3 7LD, UK

Correspondence: Helen M. McGettrick (h.m.mcgettrick@bham.ac.uk)
}

Received: 24 April 2020 Revised: 28 August 2020 Accepted: 14 October 2020

Published online: 07 January 2021 


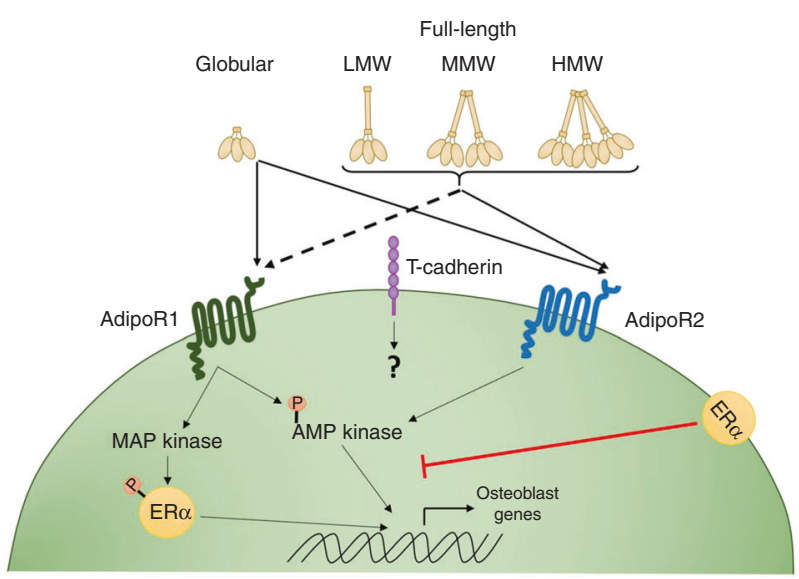

Fig. 1 Adiponectin signalling. The full-length adiponectin protein can be cleaved into smaller active components, which circulate either as it's globular domain ${ }^{7}$ or as full-length homo-complexeslow molecular weight (LMW) trimers, medium molecular weight (MMW) hexamers or high molecular weight (HMW) oligomers. ${ }^{8-10}$ Adiponectin can bind to two classical adiponectin receptors 1 and 2 (AdipoR1 and AdipoR2) ${ }^{14,15}$ leading to downstream signalling through several pathways, primarily driving AMP kinase (AMPK) and to a lesser extent activating MAP kinase (MAPK). ${ }^{16-18}$ Expression of the oestrogen receptor (ER $\alpha)$ appears to skew adiponectin receptor signalling to primarily trigger the MAPK pathway, ${ }^{61}$ which in turn phosphorylates both ER $\alpha$ and transcription factor SP1, altering downstream signalling. AdipoR1 has a higher affinity for the globular domain of adiponectin, whilst AdipoR2 displays an intermediate affinity for all adiponectin isoforms. ${ }^{21}$ In addition to the classical adiponectin receptors, HMW and MMW adiponectin can also interact with T-cadherin (cadherin-13; CDH13), ${ }^{1,20}$ although the downstream signalling and functional outcomes from these interactions are currently unknown

demonstrating higher affinity of AdipoR1 for globular adiponectin, whilst AdipoR2 displays an intermediate affinity for all adiponectin isoforms. ${ }^{14}$ Thus, it is likely that these differing protein-receptor interactions results in divergent cellular responses to adiponectin, even within the same cell. In addition, many studies explore serum levels rather than the tissue-level expression of adiponectin, and whilst the bone is well vascularised, ${ }^{22}$ understanding the link between serum levels and local tissue effects has proved challenging.

\section{ADIPONECTIN RECEPTOR EXPRESSION IN CELLS OF THE BONE} Within the bone, precursor bone cells, osteoblasts and osteoclasts have all been reported to express the adiponectin receptors, although conflicting findings exist that are important to consider when interpreting adiponectin-signalling responses from in vitro studies. For instance, AdipoR1 and R2 mRNA and protein are detectable in murine osteoblasts, ${ }^{23}$ human osteoblast precursors (bone marrow stromal cell- BMSC and osteoblast-like cell lines) ${ }^{24,25}$ and osteoclast precursors (human peripheral blood monocytes, PBMC). ${ }^{26,27}$ In all cases, adiponectin receptor 1 was detected at significantly higher levels (up to 100-fold) than adiponectin receptor 2. Indeed in some studies expression of AdipoR2 was below the limits of detection-e.g. no AdipoR2 protein was detected in healthy human tibial osteoblasts ${ }^{28}$ nor gene expression observed in the MC3T3 murine osteoblast precursor cell line. ${ }^{29}$ The absence or lower expression of adiponectin receptor 2 on bone cells suggests that they preferentially response to globular adiponectin, which has a higher affinity for adiponectin receptor 1 than the other forms of adiponectin. ${ }^{14}$ Moreover, the majority of in vitro osteoblast models display increased expression of AdipoR1, but not AdipoR2, following differentiation, including
Saos- $2^{25}$ and $\mathrm{C} 3 \mathrm{H} 10 \mathrm{~T} 1 / 2,{ }^{24}$ a response not seen when MC3T3 were used. $^{23}$ In contrast, MC3T3 cells up-regulated AdipoR2 expression and down-regulated AdipoR1 expression upon differentiation. ${ }^{23}$ This difference in the expression pattern by MC3T3 cells upon differentiation may help to explain some of the confounding results observed between studies exploring osteoblast response to adiponectin. By contrast, in vitro osteoclastogenesis does not appear to affect the expression of adiponectin receptors at either the mRNA or protein level. ${ }^{27}$

The expression of adiponectin receptors by the main precursors and mature bone cells demonstrates that all have the potential to interact with and respond to adiponectin during the different stages of bone homeostasis. However, key questions remain: What is the impact of adiponectin signalling on bone formation and turnover? How are these adiponectin-mediated effects influenced by bone damage, with age and by inflammatory diseases? Can a greater understanding of adiponectin regulation of bone homeostasis lead to novel strategies to repair injured and damaged bone?

\section{IMPACT OF ADIPONECTIN ON OSTEOBLASTOGENESIS AND ACTIVITY}

Bone marrow adipocytes continuously release adipokines into the bone niche, bathing all cells including osteoblast and osteoclast progenitors in adiponectin. ${ }^{30,31}$ Indeed, the limited available data indicates that within the bone marrow niche adiponectin acts to promote osteoblastogenesis, whilst simultaneously inhibiting osteoclastogenesis (Table 1). ${ }^{24,32-35}$ Addition of full-length ${ }^{24,35}$ or globular $^{36}$ adiponectin induces the expression of the osteogenicrelated genes osteopontin ${ }^{24,36}$ and alkaline phosphatase ${ }^{24,35,36}$ in the murine mesenchymal progenitor cell line, C $3 \mathrm{H} 10 \mathrm{~T} 1 / 2,{ }^{24}$ the pre-osteoblast MC3T3-E1 murine cell-line, ${ }^{35}$ and in human adipose-derived stem cells (ADSC) in vitro. ${ }^{36}$ Moreover, BMSCs from 5 week old adiponectin knockout mice exhibited reduced gene expression of key osteoblast promoting lysine specific histone demethylases (KDM4B and KDM6B) when compared to wildtype mice infused with either globular or full-length adiponectin. ${ }^{37}$ Absence of KDM4B and KDM6B reportedly increased gene expression of PPARG in human BMSC and thus switched the differentiation fate from osteogenic to adipogenic in vitro. $^{38}$ Indeed, the presence of fatty bone marrow in adiponectin knockout mice was attributed to reduced KDM4B and $\mathrm{KDM} 6 \mathrm{~B}$ expression in BMSCs, triggering adipogenesis and ultimately causing a reduction in osteoblasts and increase in adipocytes on the trabecular surfaces. ${ }^{37}$ Furthermore, siRNA knockdown of AdipoR1 in C3H10T1/2 cells significantly reduced adiponectin-induced osteoblast differentiation in vitro. ${ }^{24}$ Supporting this, enhanced matrix mineralisation was observed in human ADSCs cultured in the presence of globular adiponectin compared to untreated controls. ${ }^{36}$ Of note, one study disagrees with the above literature: Kajimura et al., demonstrated that 6 week old adiponectin knockout mice have increased bone mass and osteoblast numbers, suggesting adiponectin inhibits bone mass accrual in young mice. ${ }^{34}$ However, no changes were observed in the gene expression of the osteoblast differentiation markers runx2 and osterix in 12-week-old bones from adiponectin knockout mice compared to the wildtype controls-suggesting that by this time point adiponectin was no longer able to limit bone formation. ${ }^{34}$ Importantly the mineralisation capacity of cells from these bones was not assessed. Bones from 10-day old adiponectin knockout mice exhibited increased cellular proliferation and reduced apoptosis. ${ }^{34}$ Indeed, treating serum-starved wildtype calvarial osteoblasts with either full-length or global adiponectin reduced proliferation and increased apoptosis rate over $24 \mathrm{~h}^{34}$ Importantly, no changes in proliferation or apoptosis have been reported in the aforementioned studies, where various osteoblasts were cultured in the presence of 


\begin{tabular}{|c|c|c|c|c|}
\hline Adiponectin Type & Species & Cell type & Effect & $\operatorname{Re}$ \\
\hline \multirow[t]{5}{*}{ Full-length } & Mouse & $\mathrm{C} 3 \mathrm{H} 10 \mathrm{~T} 1 / 2$ & $\begin{array}{l}\uparrow \text { OPN mRNA } \\
\uparrow \text { ALP mRNA }\end{array}$ & 24 \\
\hline & Mouse & МС3Т3 & $\uparrow$ Mineralisation & 35 \\
\hline & Mouse & RAW624 & $\begin{array}{l}\downarrow \text { Differentiation } \\
\uparrow \text { Apoptosis }\end{array}$ & 32 \\
\hline & Human & Mononuclear osteoclast precursor & $\begin{array}{l}\downarrow \text { Differentiation } \\
\uparrow \text { Apoptosis }\end{array}$ & 35 \\
\hline & Mouse & $\mathrm{CD} 14^{+} \mathrm{PBMC}$ & $\downarrow$ Resorption & 35 \\
\hline \multirow[t]{2}{*}{ Globular } & Human & Adipogenic stem cells & $\begin{array}{l}\uparrow \text { RUNX2, OPN, ALP mRNA } \\
\uparrow \text { Mineralisation }\end{array}$ & 36 \\
\hline & Mouse & RAW264.7 & $\begin{array}{l}\downarrow \text { Resorption } \\
\downarrow \text { Osteoclast number } \\
\uparrow \text { Apoptosis }\end{array}$ & 39 \\
\hline \multirow[t]{2}{*}{ All } & Mouse & Adiponectin KO BMSC & $\downarrow$ Adipogenic differentiation & 37 \\
\hline & Mouse & AdipoR1 siRNA KD C3H10T1/2 & $\downarrow$ Osteoblast differentiation & \\
\hline
\end{tabular}

AdipoR adiponectin receptor 1, ALPalkaline phosphatase, BMSC bone marrow stem cells, KD knock down, KO knockout, OPN osteopontin, PBMC peripheral blood monocytic cells, RUNX2 RUNX family transcription factor 2, siRNA short interfering RNA

serum. $^{24,35,36}$ Serum starvation, therefore, may account for the discrepancies in proliferation and apoptosis observed between these studies and the Kajimura et al. Overall, adiponectin appears to have a predominantly positive role in boosting pre-osteoblast differentiation and mineralisation capacity, potentially protecting the bone by inducing formation and repair.

\section{IMPACT OF ADIPONECTIN ON OSTEOCLASTOGENESIS AND ACTIVITY}

By contrast, few groups have analysed the effect of adiponectin on osteoclastogenesis to date (Table 1). Addition of full-length adiponectin significantly inhibited the ability of human mononuclear cells and murine macrophage progenitors to differentiate into mature osteoclasts when cultured in vitro in the presence of osteoclastogenic stimulating factors [macrophage colonystimulating factor and receptor activator of nuclear factor kappa$B$ ligand (RANKL)]. ${ }^{39}$ Similarly, globular adiponectin blocked RANKL-induced osteoclastogenesis of the murine monocyte cell line RAW264.7. ${ }^{39}$ Importantly these studies indicate that adiponectin reduces the ability of osteoclast precursors to mature. Akin to data on osteoblast precursors, global adiponectin treatment reduced the proliferation rate of RAW264.7 osteoclast precursors and increased their apoptosis through APPL1-mediated downregulation of Akt1 activity. ${ }^{39}$ As such it is unclear whether adiponectin mediates a direct effect on osteoclastogenesis or an indirect effect by reducing overall precursor numbers. Additional studies are urgently required to reproduce these findings and clarify the supposed anti-osteoclastogenic role of adiponectin.

\section{REGULATOR OF OSTEOBLAST AND OSTEOCLAST PROGENITOR MIGRATION}

Osteoblast progenitors must exit the bone marrow niche to migrate towards the sites of resorption and/or damage (Fig. 2). ${ }^{40}$ Indeed fate mapping experiments have revealed that $70 \%$ of the osteoblasts found replenishing the endosteal surface during homeostasis originated from the bone marrow-derived osteoblast precursors. ${ }^{41}$ In addition, YFP-positive osteoblast precursors migrated from the neighbouring bone marrow to the site of calvarial microfracture, accounting for the majority of the cells at the site of injury after 7 days when compared to the bone resident pre- and mature osteoblast. ${ }^{41}$ This process can be controlled by the CXCR4-CXCL12 axis, where high levels of CXCL12 attract CXCR4 expressing cells and retain them. ${ }^{42}$ Globular adiponectin significantly reduces expression of CXCR4 mRNA in cultured murine $\mathrm{BMSCs}^{40}$ therefore reducing the attraction of these cells to CXCL12 in the bone marrow. Similarly, adiponectin-deficient mice have higher numbers of CXCL12 positive cells within the bone marrow compared to wildtype mice, ${ }^{40}$ indicating that adiponectin regulates the exit of BMSCs from the bone marrow into the local bone environment where they can differentiate into osteoblasts. ${ }^{40,43}$ In addition, globular adiponectin enhanced BMSC migration across a Matrigel-coated Boyden chamber over $16 \mathrm{~h}$ in vitro, which was coupled with an increase in MMP9 mRNA expression. ${ }^{40}$ Moreover, systemic globular adiponectin infusion increased serum CXCL12 levels and promoted nestin ${ }^{+}$BMSC exit the bone marrow niche into the peripheral blood. ${ }^{40}$ Furthermore, therapeutic infusion of globular adiponectin significantly increased new bone formation at the site of calvarial injury, to a higher degree than seen in wildtype and adiponectin-deficient mice. ${ }^{40}$ This was attributed to enhanced migration of osteoblasts from the periphery to the injury site following adiponectin treatment, resulting in increased bone regeneration. Collectively these studies indicate that adiponectin regulates the CXCR4-CXCL12 axis within the bone marrow niche, facilitating the migratory exit of bone progenitor cells from this niche into the periphery in health and in response to injury. Comparably, osteoclast precursors such as PBMCs, express CXCR4 ${ }^{44}$ and therefore osteoclast migration out the bone may mirror the mechanisms described for osteoblasts. Yet, few studies have examined the functional consequence of adiponectin on osteoclast migration, which are required to fully understand the overall impact of adiponectin on bone.

In addition to the CXCR4-CXCL12 axis, the bioactive lipid sphingosine-1-phosphate (S1P) - has also been reported to influence the migration of osteoblast and osteoclast precursors (Fig. 2). ${ }^{45,46} \mathrm{~S} 1 \mathrm{P}$ is synthesised intracellularly through the phosphorylation of sphingosine by the sphingosine kinases 1 and 2 , and then trafficked out of the cell via sphingosine transporters where it interacts with S1P receptors to mediate its effects. ${ }^{47}$ Elevated levels of circulating S1P are observed in adiponectin-overexpressing transgenic mice. ${ }^{17}$ However, very little is known about the possible consequence of adiponectin on S1Pregulated migration. Both osteoblast and osteoclast precursors express S1P receptors (S1PR1, S1PR2). ${ }^{48-50}$ In addition, BMSC 


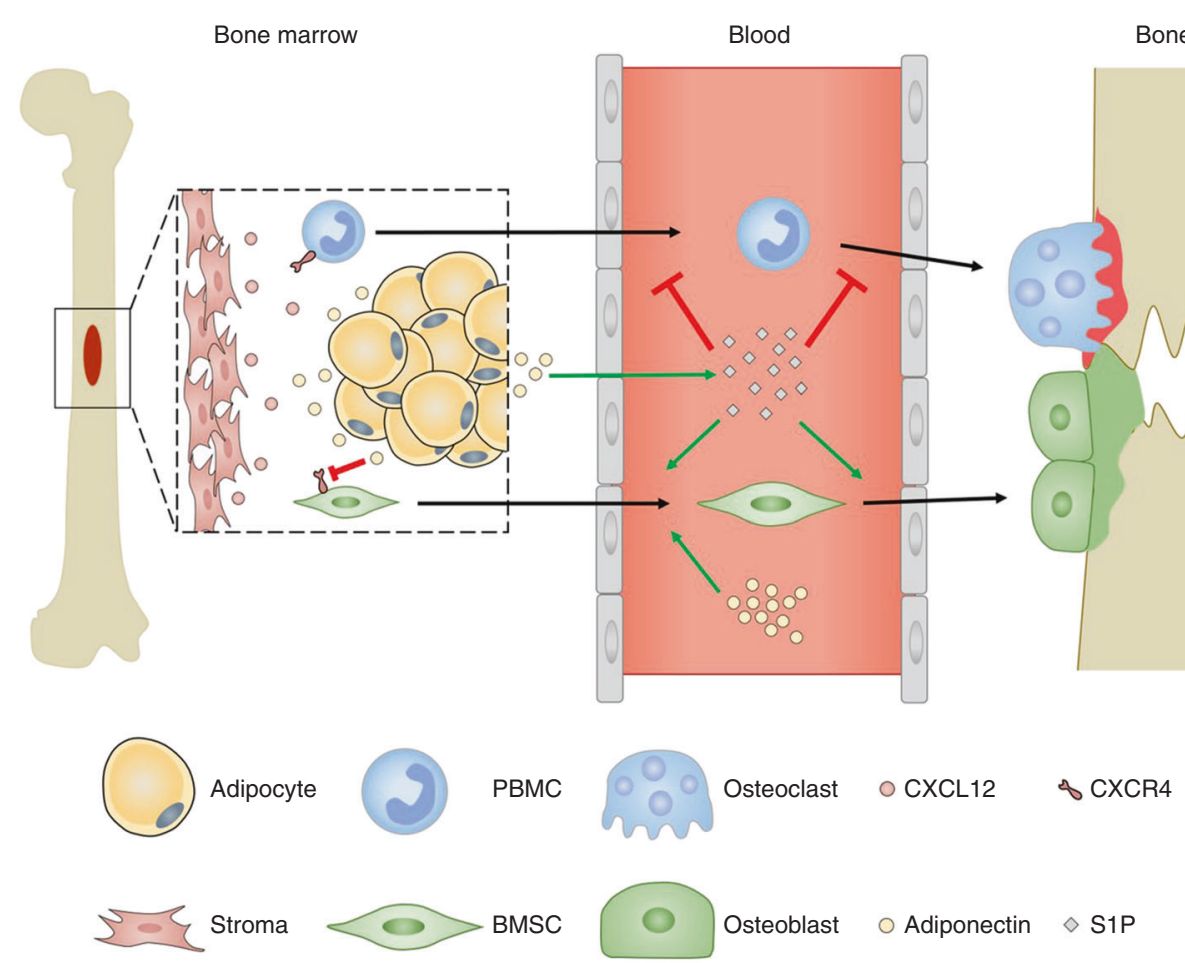

Fig. 2 Adiponectin regulation of osteoblast and osteoclast migration. Osteoblast progenitors must exit the bone marrow niche to migrate towards the sites of resorption and/or damage. In fate mapping experiments, YFP expressing bone marrow-derived osteoblast precursors migrated to the endosteal surface to replenish osteoblast populations in healthy conditions and also in response to calvarial microfracture. ${ }^{41}$ Osteoblast and osteoclast progenitors express CXCR4 and migrate towards high levels of CXCL12 causing them to be retained in the bone marrow. ${ }^{42}$ Adiponectin directly ${ }^{40}$ and through increasing S1P in the serum, ${ }^{17}$ leads to increased osteoblast progenitor migration into the circulation and to bone in health, ${ }^{48}$ which is enhanced during injury. ${ }^{41,116,117}$ In contrast, S1P chemorepels osteoclast progenitors and osteoclasts, ${ }^{51}$ leading to decreased migration to damaged sites. This ultimately maintains the balance between resorption (red) and formation (green) to ensure structured bone repair

migrate towards S1P in vitro. ${ }^{48}$ However, osteoclast precursors chemorepel from S1P, either through S1PR1/2 ${ }^{50}$ or S1PR2/3. ${ }^{51}$ In addition, sphingosine kinase 1 activity was upregulated in osteoclasts upon differentiation, ${ }^{52}$ indicating a role for osteoclast S1P release in maintaining the osteoclast-osteoblast balance. However, the impact of adiponectin in these responses remains unknown. One could postulate that direct effects of adiponectin signalling and adiponectin-induced increases in serum S1P cause the recruitment of the earliest bone precursors into the periphery, whilst simultaneously retaining pre-osteoblasts and mature osteoclasts within the bone to enable bone homeostasis and repair. Overall, these studies indicate that adiponectin increases osteoblast precursor migration, in part through CXCR4-CXCL12 axis and S1P, to favour bone formation. However, further work is required to fully understand these interactions and their functional consequences, as well as other potential molecular mechanisms underpinning adiponectin regulation of osteoblast and osteoclast migration.

\section{ROLE OF ADIPONECTIN IN THE REGULATION OF BONE HOMEOSTASIS}

In health and ageing

The actions of adiponectin in homeostatic bone turnover have been extensively explored in human and murine in vivo and in vitro studies in order to understand how it can be targeted in disease states (Tables 2 and 3). Of note, these studies overwhelmingly focus on juvenile or adult models, where BMAT and WAT are fully developed, and can both contribute to bone adiponectin levels. No studies to date have examined the role of adiponectin in foetal and neonatal bone development.
Global overproduction of full-length adiponectin significantly increases trabecular bone mass and reduces bone resorption (as measured by plasma cross-linked N-telopeptides of type I collagen (nTx) levels) over a 2 -week period in young 8 week old mice. ${ }^{35}$ Similarly, higher bone mineral density (BMD) and reduced number of TRAP5b-positive osteoclasts were observed in aged (56 weeks) AdipoR1-overexpressing transgenic mice, but not in younger mice aged 8 or 32 weeks. ${ }^{33}$ Likewise, AdipoR1-deficient mice have decreased trabecular bone volume, thickness, number and spacing, along with reduced osteoblast numbers. ${ }^{53}$ Similarly, 36 week old adiponectin knockout mice also display severe low bone mass affecting all skeletal elements, yet this was linked to decreased number and proliferation ability of osteoblasts rather than effects on osteoclasts. ${ }^{34}$ Interestingly osteoclast numbers were unaffected by loss of AdipoR 1 in young mice aged 4 and 30 weeks. $^{53}$ Collectively, these studies suggest that age may significantly alter the effects of adiponectin on osteoclasts. Moreover, they suggest that adiponectin-signalling through AdipoR1 is critical for maintaining osteoblast survival and activity with age and may also regulate osteoclast apoptosis.

Mirroring the in vivo findings described above, bone explants from 3-day old wildtype mice implanted subcutaneously into the flank of adiponectin knockout mice had reduced trabecular volume and cortical bone parameters $2-4$ weeks after implantation when compared to those implanted into wildtype mice, ${ }^{39}$ indicating that systemic levels of adiponectin were sufficient to impact normal bone remodelling. In vitro studies support these findings, with full-length adiponectin stimulating bone matrix deposition and hydroxyapatite formation by MC3T3-E1 cells, and reducing its resorption by $\mathrm{CD} 14^{+}$PBMC osteoclast precursors. ${ }^{35}$ Collectively these data indicate that adiponectin promotes bone 


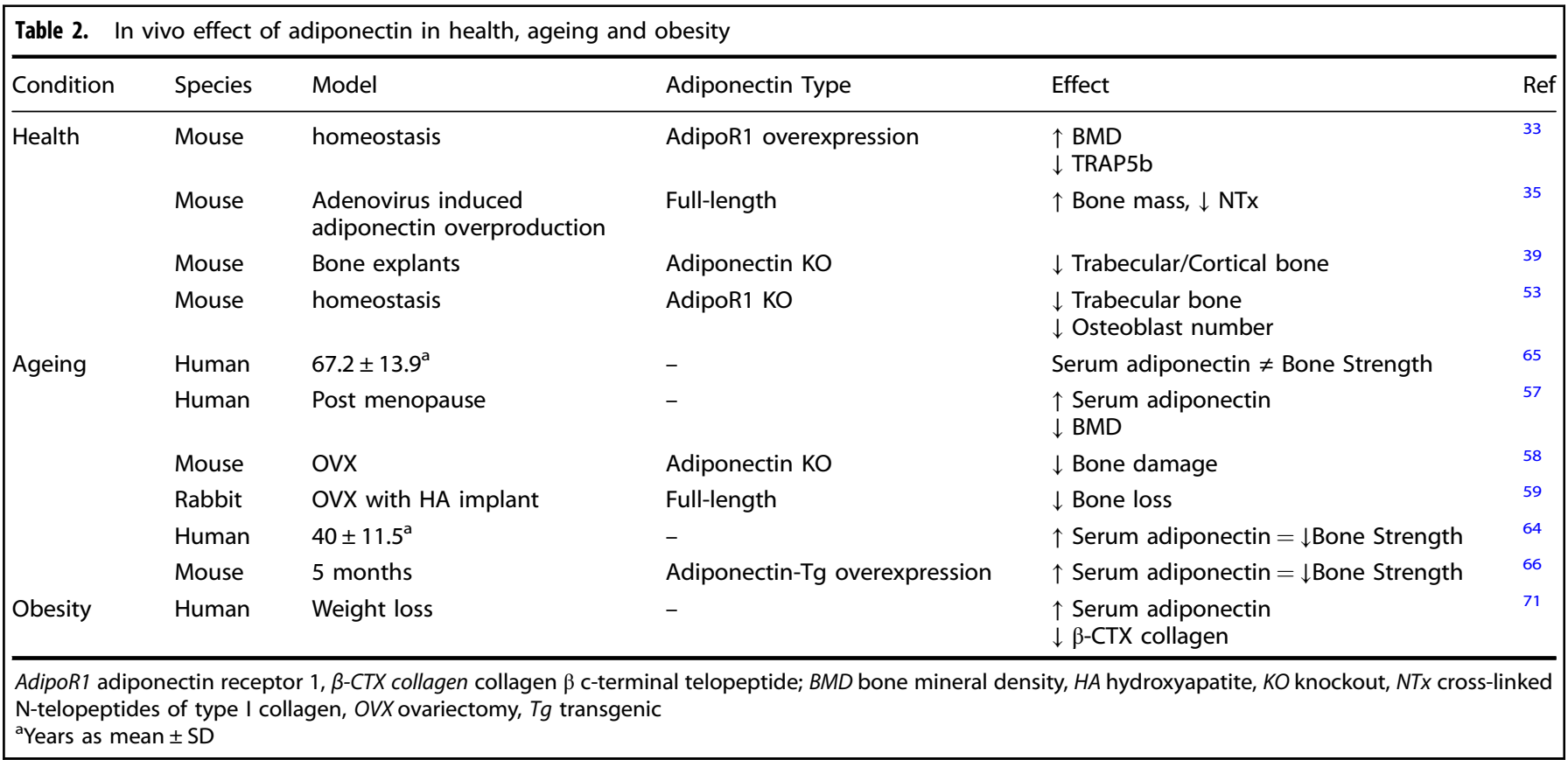

\begin{tabular}{|c|c|c|c|c|c|c|}
\hline Disease & Species & Model & Adiponectin Type & Cell & Effect & Ref \\
\hline \multirow[t]{2}{*}{ OA } & Human & - & - & - & $\uparrow$ Serum adiponectin in erosive OA & 86 \\
\hline & Mouse & STR/Ort & - & - & $\uparrow$ Serum adiponectin $=\downarrow$ Severity & \\
\hline \multirow[t]{3}{*}{ Periodontitis } & Mouse & Experimental periodontitis & Adiponectin $\mathrm{KO}$ & - & $\uparrow$ Osteoclast number, $\downarrow$ Bone strength & \\
\hline & & & Globular & - & $\uparrow$ Osteoclast number, $\downarrow$ Bone loss & 89 \\
\hline & Mouse & In vitro LPS inflammation & Globular & RAW624 & $\begin{array}{l}\downarrow \text { TNF- } \alpha \text { and IL1 } \beta \\
\uparrow \text { IL10 }\end{array}$ & 90 \\
\hline \multirow[t]{8}{*}{ RA } & Human & - & Full-length & - & $\uparrow$ Serum adiponectin & 91 \\
\hline & Human & - & Full-length & - & $\uparrow$ Plasma adiponectin & 91,92 \\
\hline & Human & Ex vivo culture & Unknown & Osteoblast & $\begin{array}{l}\downarrow \text { Osterix mRNA } \\
\uparrow \text { OPG mRNA }\end{array}$ & 94 \\
\hline & Human & Ex vivo culture & Unknown & Osteoclast & $\uparrow$ MMP9 \& TRAP mRNA & 94 \\
\hline & Mouse & $\mathrm{CIA}$ & Full-length & - & $\uparrow$ Damage, $\downarrow$ BMD, $\uparrow$ Osteoclast number & 98 \\
\hline & Mouse & $\mathrm{CIA}$ & Globular & - & $\downarrow \mathrm{BMD}$ & 99 \\
\hline & Mouse & $\mathrm{CIA}$ & Unknown & - & $\downarrow$ Score & 101 \\
\hline & Mouse & $\mathrm{ClA}$ & Full-length & - & $\downarrow$ Score, $\downarrow$ MMP3 & 102 \\
\hline \multirow[t]{3}{*}{ Osteosarcoma } & Human & 16-year-old patient & - & - & $\uparrow$ Adiponectin mRNA in diseased bone & 105 \\
\hline & Mouse & In vitro & Globular & Saos-2 & $\uparrow$ Viability & 106 \\
\hline & Mouse & In vitro & AdipoR inhibitor & Saos-2 & $\downarrow$ Proliferation & 108 \\
\hline \multirow[t]{2}{*}{ Cancer metastasis } & Mouse & 5TGMI cell cancer & Adiponectin KO & - & $\uparrow$ Bone damage & 111 \\
\hline & & & L-4F (HMW adiponectin) & - & $\downarrow$ Bone damage & 111 \\
\hline OI & Murine & Col1a1 mutation & - & - & $\downarrow$ Body fat & 113 \\
\hline \multirow[t]{2}{*}{ Osteopetrosis } & Murine & Obesity induced & - & - & Exercise $=\downarrow$ Aberrant bone growth & 114 \\
\hline & Human & Infantile osteopetrosis & Full-length & BMMC & $\begin{array}{l}\downarrow \text { Adiponectin release } \\
\downarrow \text { Adipogenic differentiation }\end{array}$ & 115 \\
\hline
\end{tabular}

AdipoR adiponectin receptor, $B M M C$ bone marrow mononuclear cells, BMD bone mineral density, CIA collagen induced arthritis, $H M W$ high molecular weightb, LPS lipopolysaccharide, MMP matrix metalloproteinase, KO knockout, OA osteoarthritis, Ol osteogenesis imperfecta, OPG osteoprotegerin, RA rheumatoid arthritis, Score clinical score, SRT/Ort murine strain prone to OA

formation and limits bone resorption in healthy young and old mice (Fig. 3A), where exogenous adiponectin may serve to maintain bone mass during age-related bone loss. Moreover, therapeutically adjusting the circulating levels of adiponectin may result in beneficial effects on the bone, avoiding the need to develop drugs that specifically target the bone. Importantly, no studies have yet explored the role of adiponectin in the development and maturation of healthy human bones either in vivo or ex vivo. 

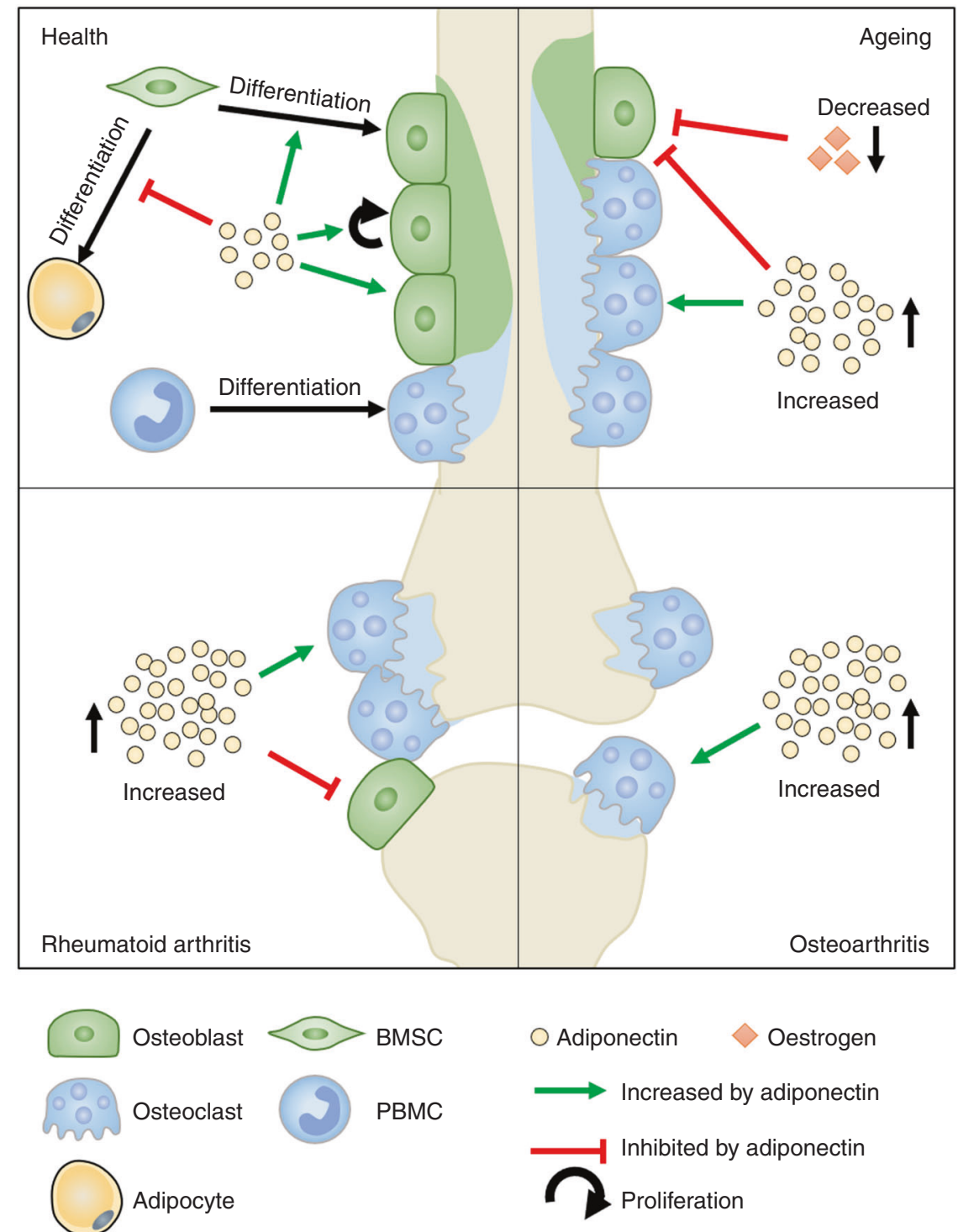

Fig. 3 Adiponectin signalling in bone. Under healthy conditions, adiponectin supports the proliferation, migration, mineralisation and survival of osteoblasts (green), whilst decreasing osteoclastogenesis and resorption (blue), ultimately leading to bone homeostasis. By contrast, these traits are broadly dysregulated in bones as we age and in patients with obesity or diseases such as rheumatoid arthritis and osteoarthritis: Increases in adiponectin, or changes in environmental cues (including levels of oestrogen) that impact the downstream signalling pathways triggered by adiponectin (e.g. MAPK vs AMPK), pathologically tip the balance in favour of bone resorption and damage (blue) in these conditions

Both BMAT and serum adiponectin increase significantly with age $^{54}$ and in osteoporosis 55,56 and are broadly thought to negatively correlate with BMD in humans (Table 2). For example, post-menopausal women have higher serum adiponectin levels and reduced BMD compared to pre-menopausal women of the same age. ${ }^{57}$ Interestingly, a lack of adiponectin protects young mice from ovariectomy-induced bone loss 10 weeks after surgery. ${ }^{58}$ In contrast, sustained local release of low levels of therapeutic full-length adiponectin, from a hydroxyapatiteMatrigel implant, protected against ovariectomy-induced trabecular bone loss in the mandibles of rabbits. ${ }^{59}$ These studies suggest that the absence or consistently maintained low levels of adiponectin protect against menopause (hormonal) induced bone loss, maintaining BMD (Fig. 3B). Indeed, this would mitigate against the elevated levels of adiponectin anticipated in response to the increased BMAT levels observed with age (as reviewed by ${ }^{60}$ ). This contrasts with healthy young bone (as discussed above), where higher levels of adiponectin are thought to promote bone formation and limit bone loss to maintain BMD. The exact mechanisms regulating the differential effects of adiponectin with age/in post-menopausal state remains unclear and requires further investigation. One possible explanation is the ability of the oestrogen receptor (ERa) to influence the downstream signalling response from the adiponectin receptors - where the presence of ERa triggers the MAPK pathway, rather than activating AMPK as would normally occur (Fig. 1). ${ }^{61}$ Given these changes occur in the absence of oestrogen ${ }^{61}$ as would be seen in post-menopausal women, it is unlikely that it is signalling through the ERa is responsible for these changes, but rather highlights the possibility that ERa acts as a co-receptor for the adiponectin receptors to alters the downstream signalling that is observed in response to adiponectin. Importantly, murine ovariectomy increased ERa mRNA expression in multiple tissues, ${ }^{62}$ and therefore is it likely that elevated ERa expression promotes adiponectin 
signalling through the MAPK pathway in these tissues and potentially contributes to menopause-induced bone loss.

Age-related decline in BMD is associated with increased susceptibility to microfractures in humans, ${ }^{63}$ however very few studies have directly examined the effect of adiponectin on bone strength. High circulating levels of adiponectin negatively correlate with bone strength and reduced maximal load in middle-aged overweight men (mean \pm S.D.--age $40 \pm 11.5$ years, BMI $25 \pm 6.2) .{ }^{64}$ By contrast, no link has been found between circulating adiponectin levels and the frequency of fracture in the men over the age of 70 with an average $\mathrm{BMI} \sim 26$ in this correlative study. ${ }^{65}$ These limited data appear to suggest that circulating levels of adiponectin influences bone strength and risk of fracture at least in overweight middle-aged men. However, more detailed longitudinal human studies, in which confounders such as BMI are carefully controlled for, are required to fully dissect the interaction of circulating adiponectin levels with BMD and fracture rates across different age groups.

Even fewer in vivo and in vitro studies exist that have directly assessed bone strength in response to adiponectin. Agreeing with the human data, adiponectin-overexpressing transgenic mice exhibited lower bone mass and lower strength at $2,4^{33}$ and $5^{66}$ months compared to age matched wild-type controls. In addition treating 3-D cultures of human osteoblasts and osteoclast precursors in mineral forming spheres (known as osteospheres) with an unknown adiponectin isoform significantly reduced their strength, as assessed using nano-indentation; indicating weaker, more breakable bone. ${ }^{67}$ Mechanistic studies are required to elucidate the how the ageing process alters adiponectin signalling within the bone, but also systemically, to modulate BMD and strength.

In obesity and obesity-related diseases

Circulating adiponectin levels are decreased in obesity in both adults and children (young and adolescent). ${ }^{68,69}$ This is in-part due to adipocytes in the WAT acquiring a pro-inflammatory phenotype, which alters their production of various adipokines including adiponectin. ${ }^{70}$ Whether adipocytes in BMAT acquire the same obesity-linked phenotype remains unclear. Interestingly, weight loss in obese adolescents was associated with increased serum adiponectin levels coupled to lower levels of the bone resorption marker, collagen $\beta$ c-terminal telopeptide. ${ }^{71}$ Moreover, caloric restriction in mice ${ }^{11,72}$ or humans with anorexia nervosa ${ }^{73-76}$ has also been associated with an increase in bone marrow adiposity, coupled with increased adiponectin and a decrease in bone mass. Despite the link between obesity and reduced BMD (Table 2), ${ }^{69,77,78}$ most studies overlook adiponectin measurements in their analyses. Therefore, further research is needed to explore the impact of obesity in humans on adiponectin signalling in bone.

Whilst murine models can provide a more in-depth study of the effects of obesity on the bone, again none of the available literature explores the importance of adiponectin in the changes they describe. For instance, 12-weeks of high fat diet significantly reduced trabecular bone volume and number, ${ }^{79}$ and decreased the amount of cancellous bone, as well as collagen and osteoid expression observed after 23-weeks of the $\operatorname{diet}^{80}$ in wildtype mice - where these changes were linked to increases in adipocyte volume, and thus BMAT, rather than reduction in osteoblast or osteoclast numbers. Moreover, obesity significantly limited fracture repair, with no callus or connected bone observed in obese mice days after fracture unlike control animals. ${ }^{81}$ High levels of limb fractures are also observed in obese children, ${ }^{82-84}$ where abnormal BMAT and adiponectin levels may be contributing to reduced bone strengthen and delayed repair.

Obesity increases the risk of patients developing osteoarthritis $(\mathrm{OA})$ and therefore, it is possible that changes in adiponectin may have detrimental effects on the bones of patients with $O A$
(Table 3). ${ }^{77,78,85}$ Human studies have revealed higher levels of adiponectin in a meta-analysis of patients with more advanced $O A$ compared to BMI matched patients with new onset $O A ;{ }^{78}$ and in the serum of women with erosive $\mathrm{OA}$ in the hand compared to non-erosive disease. ${ }^{86}$ In contrast, serum adiponectin concentrations negatively correlated with cartilage lesions and OA severity in adolescent ( 26 weeks old) STR/Ort mice, suggesting adiponectin has a protective role in a human-like murine OA model. ${ }^{87}$ It is difficult to make any definitive conclusions based on the currently available data on whether changes in adiponectin levels represent part of the molecular mechanism driving pathology of $O A$, or are part of the protective response to the on-going joint damage. As such these concepts need to be explored further taking into account the aforementioned confounding factors.

\section{In inflammatory disease}

Periodontitis. Periodontitis is the most common inflammatory bone disease worldwide, affecting $60 \%$ of $>75$-year olds. ${ }^{88}$ Despite this, we have a limited understanding of the importance of adiponectin in periodontal bone damage; with most of the evidence to date generated using murine models (Table 3 ). For instance, following induction of experimental periodontitis by coating molars with a bacterial broth, adiponectin knockout mice have increased osteoclast numbers in palatal bone compared to wildtype control mice. ${ }^{89}$ Moreover, globular adiponectin therapy reduced the number of $\mathrm{TRAP}^{+}$osteoclasts in the inflamed palatal bone in adiponectin knockout mice, leading to a concomitant reduction in alveolar bone loss. ${ }^{89}$ In vitro, RAW264 osteoclast precursors treated with lipopolysaccharide (LPS) and globular adiponectin showed reduced pro-inflammatory cytokine secretion (TNF- $\alpha$ and IL-1 $\beta$ ) and increased anti-inflammatory IL-10 release, compared to LPS treatment alone. ${ }^{90}$ Clearly further studies are required, but the data available suggest that adiponectin exerts a direct anti-osteoclastogenic role during periodontitis.

Rheumatoid arthritis. Patients with rheumatoid arthritis (RA) have elevated levels of adiponectin in plasma ${ }^{91,92}$ and synovial fluid, ${ }^{93}$ compared to sex, age and BMI-matched control samples. These findings correlate with radiographic erosions suggesting a role for adiponectin in disease pathology (Table 3). ${ }^{92,93}$ Moreover, adiponectin stimulated MMP9 and TRAP expression in cultured human osteoclasts from RA patients ${ }^{94}$ - unlike what has been reported for healthy osteoblasts (see above). Importantly these data suggest that the chronic inflammatory environment in RA switches the adiponectin response in osteoclasts from being antiosteoclastogenic to a pathological pro-resorptive response. However, osteoblasts isolated from trabecular bone of RA patients cultured with adiponectin showed reduced mRNA expression of osteoblast differentiation marker osterix and increased osteoprotegerin (RANKL competitive inhibitor). ${ }^{94}$ Overall these data indicate that adiponectin contributes to bone damage in rheumatoid arthritis: where it directly reduces osteoblast differentiation, whilst stimulating osteoclastogenesis leading to enhanced bone resorption (Fig. 3B). It is unclear what specific factors linked to the chronic conditions of rheumatoid arthritis are responsible for the reversal of the effects of adiponectin on osteoblasts and osteoclasts. It is highly likely to be a consequence of the multi-factorial pathological changes that occur within the joint, such as reduced adiposity within the synovium and BMAT, ${ }^{95}$ the chronic production of pro-osteoclastogenic cytokines (TNFa and RANKL ${ }^{96}$ ) and pro-inflammatory cytokines (e.g. IL-1 $1 \beta$ ) that influence expression of AdipoR 1 in the synovium, ${ }^{97}$ which act in concert to either mask the anti-osteoclastogenic effects of adiponectin or to alter adiponectin receptor-mediated signalling in an as yet unknown manner.

Despite this, preclinical animal studies have been inconclusive (Table 3). Therapeutic treatment with full length ${ }^{98}$ or globular adiponectin $^{99}$ exacerbated juxta-articular bone erosions in 
collagen induced arthritis models, with a concomitant reduction in $\mathrm{BMD},{ }^{98,99}$ bone volume to trabecular volume ratio, ${ }^{98}$ and trabecular number ${ }^{98}$ seen when compared to untreated mice ${ }^{99}$ or to mice treated with osteopontin short hairpin RNA. ${ }^{98}$ These pathological effects of adiponectin therapy have been attributed to an increase in osteoclast number and osteoclast activity - as measured by enhanced levels of RANKL mRNA expression. ${ }^{99}$ Moreover, therapeutic administration of functional blocking antibodies against MMW (KH7-33), or both MMW and HMW (KH4-8) isoforms of adiponectin, after disease onset significantly decreased arthritic clinical score and degradation in the joint cavities, when compared to arthritic mice treated with PBS. ${ }^{100}$ Whilst no specific bone parameters were measured, $\mathrm{KH} 4-8$ treatment also led to a reduction in serum RANKL concentrations when compared to controls, ${ }^{100}$ suggesting reduced osteoclast numbers and activity, and potentially bone damage in these animals. By contrast, therapeutic treatment of arthritic mice with an unknown isoform of adiponectin ${ }^{101}$ or full-length adiponec$\operatorname{tin}^{102}$ at first signs of inflammation reduced the histopathological score (a composite measure of inflammatory cell infiltration, synovial hyperplasia, and bone destruction) when compared to untreated controls. Of note, these studies did not directly measure changes in bone anatomy following adiponectin therapy, therefore it is unclear whether the reduction in histopathological score observed equated to reduced bone damage. Supporting this possibility, the collagen-matrix degrading metalloproteinase, MMP3, was expressed at significantly lower levels in arthritic joints treated with adiponectin than the contralateral PBS treated joints. ${ }^{102}$ There are clear experimental differences between the studies cited above, which might account for the discrepancies in the reported effects. For example, the studies reporting proarthritic effects administered adiponectin a maximum of 3 times a week, whereas mice displaying anti-arthritic responses were given daily injections of adiponectin. Such different treatment regimens will alter the absolute concentration of adiponectin experienced by cells at a given time and thus their responses, which in turn will impact the pathological responses observed. Further research is urgently needed to clarify the role of adiponectin therapy on bone damage in murine models of inflammatory arthritis.

\section{CANCER AND RARE BONE DISEASES}

\section{Cancer}

Tumour growth within the skeleton can occur through multiple mechanisms, including the inappropriate expansion and activity of osteoblasts (osteosarcoma) ${ }^{103}$ or more commonly as a result of tumour metastasis, often seen in advanced breast cancers. ${ }^{104}$ Assessing the impact of adiponectin in osteosarcoma is very challenging: primary tumours are extremely rare (1 in 100,000) and osteosarcoma cell lines (e.g. Saos-2 and MG-63) are frequently used as "normal" immortalised osteoblasts in in vitro studies. ${ }^{105}$ As such limited data exists on adiponectin effects on bone cancer development and progression (Table 3). RNA-sequencing analysis revealed higher adiponectin gene expression in the bone from a single patient with primary osteosarcoma compared to the patient's own healthy bone tissue, ${ }^{105}$ although analysis of more patient samples is required to make any definitive conclusions. In vitro, globular adiponectin increased the viability of the human Saos2 osteosarcoma cell line, but reduced the activity of the promineralisation enzyme, alkaline phosphatase, in supernatants. ${ }^{105}$ By contrast, the adiponectin receptor agonist, AdipoRon, decreased the proliferation of Saos-2 cells in vitro. ${ }^{106}$ Given that AdipoR1 has a higher affinity for globular adiponectin, it is possible that increased signalling through AdipoR1 compared to AdipoR2 may promote abnormal osteoblast proliferation contributing to osteosarcoma, whilst equal signalling through both receptors may be important to control normal proliferative responses in healthy bone. Indeed, the loss of AdipoR1 has been linked to reduced osteoblast survival in vitro, ${ }^{24}$ and absolute number in vivo ${ }^{53}$ under healthy conditions (as described - In health and ageing) and may represent a novel therapeutic strategy to treat osteosarcoma. It is important to note that no data are currently available on the bone phenotype in AdipoR2 deficient mice or cells. These concepts require further investigation.

Tumour metastasis to the bone results in bone damage, increased pain and is a leading cause of death in breast cancer patients. ${ }^{61,103,107}$ Divergent adiponectin responses have been reported for tumour lines in vitro based on their expression of the oestrogen receptor (ER). The non-invasive $\mathrm{ER}^{+}$MCF-7 breast cancer cell line demonstrated increased proliferation response to globular adiponectin. ${ }^{61}$ By contrast, treatment with fulllength ${ }^{108,109}$ or globular $^{61}$ adiponectin reduced cell proliferation, ${ }^{61,108,109}$ and increased apoptosis ${ }^{109}$ of the invasive ER ${ }^{-}$MDAMB-231 breast cancer cell line. Of note, adiponectin-induced signalling through the AMPK pathway in ER ${ }^{-}$MDA-MB-231 cells, whilst MAPK pathway was triggered in $\mathrm{ER}^{+}$MCF-7 cells. ${ }^{61}$ However, the effects of adiponectin on the migratory capacity of ER- cells and their ability to metastasise to the bone remains unclear; with studies reporting an increased migration of ER- cells using globular adiponectin, but no effect upon full-length adiponectin treatment. ${ }^{110}$ Moreover, inoculation of normal mice with established multiple myeloma (5TGM1) cells intravenously induced bone damage in wildtype mice, which was further exacerbated in adiponectin knockout mice. ${ }^{111}$ Furthermore, increasing HMW adiponectin levels by administering an apolipoprotein memetic peptide, L-4F, dramatically reduced bone lesions and damage, and concomitantly increased trabecular bone volume in myeloma-bearing mice compared to vehicle treated controls. ${ }^{111}$ Collectively, these data indicate that adiponectin can protect against multiple-myeloma-induced bone damage, potentially by acting directly on the tumour cell (5TGM1 cell) to induce apoptotsis. ${ }^{111}$ Clearly additional research is required to dissect the importance of oestrogen signalling and adiponectin-mediated tumour migration, as well as the contribution of different adiponectin isoforms to these responses and whether particular isoforms may be therapeutically beneficial to patients with osteosarcoma.

Osteopetrosis and osteogenesis imperfecta

Patients with rare bone diseases, such as osteogenesis imperfecta (OI) and osteopetrosis, have unorganised bone structure and increased bone frailty, ${ }^{112}$ which can severely reduce the quality of life of those affected. The role of adiponectin in these diseases has been sparsely researched (Table 3 ) and requires further investigation. In patients with $\mathrm{Ol}$, mutations in COL $1 \mathrm{~A} 1$ or COL1A2 result in increased bone fragility. ${ }^{113}$ Moreover, Col1a1 mutant mouse have reduced overall body fat content, ${ }^{113}$ suggesting that these mice have lower levels of adiponectin although this was not explicitly measured. Similarly, an osteopetrosis-like phenotype is induced in mice maintained on the obesity-inducing high carbohydrate diet, ${ }^{114}$ and where adiponectin concentrations are presumably much lower (as discussed above in the obesity section). Conversely, exerciseinduced weight loss significantly reduced aberrant bone growth in osteopetrotic mice and re-established bone homeostasis, ${ }^{114}$ indicating that increasing adiponectin levels may have therapeutic benefit in osteopetrosis. Additionally, BMSC from infantile osteopetrosis patients were unable to differentiate into adipocytes, secreting lower levels of adiponectin compared to BMSC isolated from healthy age-matched donors. ${ }^{115}$ Neither study actually measured adiponectin, yet it seems highly probable that fluctuations in its concentrations may contribute to changes in the bone. A greater understanding of adiponectin signalling and regulation of normal bone structure and strength in these rare diseases is urgently needed-based on our current knowledge treatment with adiponectin may alleviate some of the symptoms that patient's experience. 


\section{CONCLUSION}

Under healthy conditions, adiponectin supports the proliferation, migration, mineralisation and survival of osteoblasts, whilst concomitantly limiting proliferation, migration and survival in osteoclasts. On balance, this allows adiponectin to promote bone formation and limit bone resorption. By contrast, these traits are broadly dysregulated in bones following menopause and in patients with obesity or diseases such as chronic inflammation and cancer, where the loss of adiponectin, or changes in environmental cues that impact the downstream signalling pathways triggered by adiponectin (e.g. MAPK vs AMPK) pathologically tip the balance in favour of bone resorption and damage (Fig. 3). However, inconsistencies in study design and outcome measures, along with discrepancies in the observations made in animals and humans make it difficult to draw definitive conclusions that can be utilised clinically. Indeed, in-depth, largescale studies exploring adiponectin levels in multiple bone diseases, accounting for confounding factors such as age and $\mathrm{BMI}$, are needed to fully understand how adiponectin interacts with bone. Furthermore, more detailed mechanistic studies are required to understand the interaction of the different adiponectin isoforms with each of the receptors, and the impact which oestrogen receptors and other unknown molecules have on downstream signalling and the functional consequences of these. These studies are critical to further our understanding of the beneficial and pathological roles of adiponectin for a specific context, and the efficacy of targeting adiponectin or its signalling therapeutically to treat bone abnormalities and induce repair.

\section{ACKNOWLEDGEMENTS}

JWL was supported by a MRC-Versus Arthritis Centre for Musculoskeletal Ageing Research PhD studentship (MR/R502364/1). AJN was supported by an Arthritis Research UK Career Development Fellowship (21743).

\section{AUTHOR CONTRIBUTIONS}

All authors contributed to the drafting, editing and writing of the manuscript.

\section{ADDITIONAL INFORMATION}

Competing interests: The authors declare no competing interests.

\section{REFERENCES}

1. Khammissa, R. A. G. et al. The biological activities of vitamin d and its receptor in relation to calcium and bone homeostasis, cancer, immune and cardiovascular systems, skin biology, and oral health. Biomed. Res. Int. 2018, 1-9 (2018).

2. Balogh, E., Paragh, G. \& Jeney, V. Influence of iron on bone homeostasis. Pharmaceuticals 11, 107 (2018).

3. Penido, M. G. M. G. \& Alon, U. S. Phosphate homeostasis and its role in bone health. Pediatr. Nephrol. 27, 2039-2048 (2012).

4. Arita, Y. et al. Paradoxical decrease of an adipose-specific protein, adiponectin, in obesity. Biochem. Biophys. Res. Commun. 257, 79-83 (1999).

5. Hotta, K. et al. Plasma concentrations of a novel, adipose-specific protein, adiponectin, in type 2 diabetic patients. Arterioscler. Thromb. Vasc. Biol. 20, 1595-1599 (2000).

6. Scherer, P. E., Williams, S., Fogliano, M., Baldini, G. \& Lodish, H. F. A novel serum protein similar to $\mathrm{C} 1 \mathrm{q}$, produced exclusively in adipocytes. J. Biol. Chem. 270, 26746-26749 (1995)

7. Fruebis, J. et al. Proteolytic cleavage product of 30-kDa adipocyte complementrelated protein increases fatty acid oxidation in muscle and causes weight loss in mice. Proc. Natl. Acad. Sci. U.S.A. 98, 2005-2010 (2012).

8. Mangge, $\mathrm{H}$. et al. Preatherosclerosis and adiponectin subfractions in obese adolescents. Obesity 16, 2578-2584 (2008).

9. Waki, H. et al. Impaired multimerization of human adiponectin mutants associated with diabetes. Molecular structure and multimer formation of adiponectin. J. Biol. Chem. 278, 40352-40363 (2003).

10. Hada, Y. et al. Selective purification and characterization of adiponectin multimer species from human plasma. Biochem. Biophys. Res. Commun. 356, 487-493 (2007).
11. Cawthorn, W. P. et al. Bone marrow adipose tissue is an endocrine organ that contributes to increased circulating adiponectin during caloric restriction. Cell Metab. 20, 368-375 (2014).

12. Suchacki, K. J. et al. Bone marrow adipose tissue is a unique adipose subtype with distinct roles in glucose homeostasis. Nat. Commun. 11, 3097 (2020).

13. L Newton, A. J., Hanks, L., Davis, M. \& Casazza, K. The relationships among total body fat, bone mineral content and bone marrow adipose tissue in earlypubertal girls. Bonekey Rep. 2, 315 (2013).

14. Yamauchi, T. et al. Cloning of adiponectin receptors that mediate antidiabetic metabolic effects. Nature 423, 762-769 (2003).

15. Yamauchi, T., Iwabu, M., Okada-Iwabu, M. \& Kadowaki, T. Adiponectin receptors: a review of their structure, function and how they work. Best Pract. Res. Clin. Endocrinol. Metab. 28, 15-23 (2014).

16. Kadowaki, T. \& Yamauchi, T. Adiponectin receptor signaling: a new layer to the current model. Cell Metab. 13, 123-124 (2011).

17. Holland, W. L. et al. Receptor-mediated activation of ceramidase activity initiates the pleiotropic actions of adiponectin. Nat. Med. 17, 55-63 (2011).

18. Obeid, S. \& Hebbard, L. Role of adiponectin and its receptors in cancer. Cancer Biol. Med. 9, 213-220 (2012).

19. $\mathrm{Wu}, \mathrm{Y}$. et al. Genome-wide association study for adiponectin levels in filipino women identifies $\mathrm{CDH} 13$ and a novel uncommon haplotype at KNG1-ADIPOQ. Hum. Mol. Genet. 19, 4955-4964 (2010).

20. Hug, $C$. et al. T-cadherin is a receptor for hexameric and high-molecular-weight forms of Acrp30/adiponectin. Proc. Natl. Acad. Sci. U.S.A. 101, 10308-10313 (2004).

21. Yamauchi, T. et al. Targeted disruption of AdipoR1 and AdipoR2 causes abrogation of adiponectin binding and metabolic actions. Nat. Med. 13, 332-339 (2007).

22. Ramasamy, S. K. Structure and functions of blood vessels and vascular niches in bone. Stem Cells Int. 2017, 1-10 (2017).

23. KAMADA, A. et al. Gene expression of adiponectin receptors during osteoblastic differentiation. J. Oral. Tissue Eng. 15, 102-108 (2017).

24. Hyun, W. L. et al. Adiponectin stimulates osteoblast differentiation through induction of COX2 in mesenchymal progenitor cells. Stem Cells 27, 2254-2262 (2009).

25. Pacheco-Pantoja, E. L., Fraser, W. D., Wilson, P. J. M. \& Gallagher, J. A. Differential effects of adiponectin in osteoblast-like cells. J. Recept. Signal Transduct. 34, 351-360 (2014).

26. Pang, T. T. L. et al. Inhibition of islet immunoreactivity by adiponectin is attenuated in human type 1 diabetes. J. Clin. Endocrinol. Metab. 98, E418-E428 (2013).

27. Pacheco-Pantoja, E. L., Waring, V. J., Wilson, P. J. M., Fraser, W. D. \& Gallagher, J. A. Adiponectin receptors are present in RANK-L-induced multinucleated osteoclast-like cells. J. Recept. Signal Transduct. 33, 291-297 (2013).

28. Luo, X. H. et al. Adiponectin stimulates human osteoblasts proliferation and differentiation via the MAPK signaling pathway. Exp. Cell Res. 309, 99-109 (2005).

29. Berner, H. S. et al. Adiponectin and its receptors are expressed in bone-forming cells. Bone 35, 842-849 (2004).

30. Fazeli, P. K. et al. Marrow fat and bone-new perspectives. J. Clin. Endocrinol. Metab. 98, 935-945 (2013).

31. DiMascio, L. et al. Identification of adiponectin as a novel hemopoietic stem cell growth factor. J. Immunol. 178, 3511-3520 (2007).

32. Wu, X., Huang, L. \& Liu, J. Effects of adiponectin on osteoclastogenesis from mouse bone marrow-derived monocytes. Exp. Ther. Med. 17, 1228-1233 (2019).

33. Lin, Y. Y. et al. Adiponectin receptor 1 regulates bone formation and osteoblast differentiation by GSK-3 $\beta / \beta$-Catenin signaling in mice. Bone 64, 147-154 (2014).

34. Kajimura, D. et al. Adiponectin regulates bone mass via opposite central and peripheral mechanisms through foxo1. Cell Metab. 17, 901-915 (2013).

35. Oshima, K. et al. Adiponectin increases bone mass by suppressing osteoclast and activating osteoblast. Biochem. Biophys. Res. Commun. 331, 520-526 (2005).

36. Chen, T., Wu, Y. W., Lu, H., Guo, Y. \& Tang, Z. H. Adiponectin enhances osteogenic differentiation in human adipose-derived stem cells by activating the APPL1-AMPK signaling pathway. Biochem. Biophys. Res. Commun. 461, 237-242 (2015).

37. $\mathrm{Wu}, \mathrm{Y}$. et al. Central adiponectin administration reveals new regulatory mechanisms of bone metabolism in mice. Am. J. Physiol. Metab. 306, E1418-E1430 (2014).

38. Ye, L. et al. Histone demethylases KDM4B and KDM6B promotes osteogenic differentiation of human MSCs. Cell Stem Cell 11, 50-61 (2012).

39. Tu, Q. et al. Adiponectin inhibits osteoclastogenesis and bone resorption via APPL1-mediated suppression of Akt1. J. Biol. Chem. 286, 12542-12553 (2011).

40. $\mathrm{Yu}, \mathrm{L}$. et al. Adiponectin regulates bone marrow mesenchymal stem cell niche through a unique signal transduction pathway: an approach for treating bone disease in diabetes. Stem Cells 33, 240-252 (2015). 
41. Park, D. et al. Endogenous bone marrow MSCs are dynamic, fate-restricted participants in bone maintenance and regeneration. Cell Stem Cell 10, 259-272 (2012).

42. Döring, Y., Pawig, L., Weber, C. \& Noels, H. The CXCL12/CXCR4 chemokine ligand/receptor axis in cardiovascular disease. Front. Physiol 5, 212 (2014).

43. Colnot, C. Skeletal cell fate decisions within periosteum and bone marrow during bone regeneration. J. Bone Miner. Res. 24, 274-282 (2009).

44. Michaud, J., Im, D.-S. \& Hla, T. Inhibitory role of sphingosine 1-phosphate receptor 2 in macrophage recruitment during Inflammation. J. Immunol. 184, 1475-1483 (2010).

45. Sartawi, Z., Schipani, E., Ryan, K. B. \& Waeber, C. Sphingosine 1-phosphate (S1P) signalling: Role in bone biology and potential therapeutic target for bone repair. Pharmacol. Res. 125, 232-245 (2017).

46. Meshcheryakova, A., Mechtcheriakova, D. \& Pietschmann, P. Sphingosine 1phosphate signaling in bone remodeling: multifaceted roles and therapeutic potential. Exp. Opin. Ther. Targets 21, 725-737 (2017).

47. Mendelson, K., Evans, T. \& Hla, T. Sphingosine 1-phosphate signalling. Development 141, 5-9 (2014).

48. Li, C. et al. Homing of bone marrow mesenchymal stem cells mediated by sphingosine 1-phosphate contributes to liver fibrosis. J. Hepatol. 50, 1174-1183 (2009).

49. Ishii, M. et al. Sphingosine-1-phosphate mobilizes osteoclast precursors and regulates bone homeostasis. Nature 458, 524-528 (2009).

50. Ishii, M., Kikuta, J., Shimazu, Y., Meier-Schellersheim, M. \& Germain, R. N. Chemorepulsion by blood S1P regulates osteoclast precursor mobilization and bone remodeling in vivo. J. Exp. Med 207, 2793-2798 (2010).

51. Yang, L. et al. Sphingosine 1-phosphate receptor 2 and 3 mediate bone marrowderived monocyte/macrophage motility in cholestatic liver injury in mice. Sci. Rep. 5, 13423 (2015).

52. Ryu, J. et al. Sphingosine 1-phosphate as a regulator of osteoclast differentiation and osteoclast-osteoblast coupling. EMBO J. 25, 5840-5851 (2006).

53. Aneka Sowman, Sam Olechnowicz \& James Edwards. OC9: sarcopenia is negatively related to osteogenic impacts achieved through habitual physical activity: findings from a population-based cohort of older females, Bone Research Society, Annual Meeting 2017 Proceedings. 25-27 June 2017, Bristol, UK. J Musculoskeletal Neuronal Interactions. 18, 108-151 (2018).

54. Justesen, J. et al. Adipocyte tissue volume in bone marrow is increased with aging and in patients with osteoporosis. Biogerontology 2, 165-171 (2001).

55. Li, G. W. et al. Quantitative evaluation of vertebral marrow adipose tissue in postmenopausal female using MRI chemical shift-based water-fat separation. Clin. Radiol. 69, 254-262 (2014).

56. Syed, F. A. et al. Effects of estrogen therapy on bone marrow adipocytes in postmenopausal osteoporotic women. Osteoporos. Int. 19, 1323-1330 (2008).

57. Jürimäe, J. \& Jürimäe, T. Adiponectin is a predictor of bone mineral density in middle-aged premenopausal women. Osteoporos. Int. 18, 1253-1259 (2007).

58. Wang, F. et al. Deficiency of adiponectin protects against ovariectomy-induced osteoporosis in mice. PLoS One 8, e68497 (2013).

59. Luo, E. et al. Sustained release of adiponectin improves osteogenesis around hydroxyapatite implants by suppressing osteoclast activity in ovariectomized rabbits. Acta Biomater. 8, 734-743 (2012).

60. Rinotas, V. \& Douni, E. Molecular interaction of BMAT with bone. Curr. Mol. Biol. Rep. 4, 34-40 (2018).

61. Mauro, L. et al. Estrogen receptor-a drives adiponectin effects on cyclin D1 expression in breast cancer cells. FASEB J. 29, 2150-2160 (2015).

62. Mohamed, M. K. \& Abdel-Rahman, A. A. Effect of long-term ovariectomy and estrogen replacement on the expression of estrogen receptor gene in female rats. Eur. J. Endocrinol. 142, 307-314 (2000).

63. Wong, S. Y. P., Kariks, J., Evans, R. A., Dunstan, C. R. \& Hills, E. The effect of age on bone composition and viability in the femoral head. J. Bone Jt. Surg. 67, 274-283 (1985).

64. Tan, C. O. et al. Adiponectin is associated with bone strength and fracture history in paralyzed men with spinal cord injury. Osteoporos. Int. 25, 2599-2607 (2014)

65. Bacchetta, J. et al. The relationship between adipokines, osteocalcin and bone quality in chronic kidney disease. Nephrol. Dial. Transpl. 24, 3120-3125 (2009).

66. Rutkowski, J. M. et al. Adiponectin alters renal calcium and phosphate excretion through regulation of klotho expression. Kidney Int. 91, 324-337 (2017).

67. Haugen, S. et al. Adiponectin reduces bone stiffness: verified in a threedimensional artificial human bone model In Vitro. Front. Endocrinol. 9, 236 (2018).

68. Panagopoulou, P. et al. Adiponectin and insulin resistance in childhood obesity. J. Pediatr. Gastroenterol. Nutr. 47, 356-362 (2008).

69. Landrier, J. F. et al. Reduced adiponectin expression after high-fat diet is associated with selective up-regulation of ALDH1A1 and further retinoic acid receptor signaling in adipose tissue. FASEB J. 31, 203-211 (2017).
70. Greenberg, A. S. \& Obin, M. S. Obesity and the role of adipose tissue in inflammation and metabolism. Am J Clin Nutr 83, 461S-465S (2006).

71. Campos, R. M. et al. Relationship between adiponectin and leptin on osteocalcin in obese adolescents during weight loss therapy. Arch. Endocrinol. Metab. 62, 275-284 (2018).

72. Devlin, M. J. et al. Caloric restriction leads to high marrow adiposity and low bone mass in growing mice. J. Bone Miner. Res. 25, 2078-2088 (2010).

73. Abella, E. et al. Bone marrow changes in anorexia nervosa are correlated with the amount of weight loss and not with other clinical findings NERVOSA 582. Am. J. Clin. Pathol. 118, 582-588 (2002).

74. Tagami, T. et al. Adiponectin in anorexia nervosa and bulimia nervosa. J. Clin. Endocrinol. Metab. 89, 1833-1837 (2004)

75. Bredella, M. A. et al. Increased bone marrow fat in anorexia nervosa. J. Clin. Endocrinol. Metab. 94, 2129-2136 (2009).

76. Iwahashi, H. et al. Plasma adiponectin levels in women with Anorexia Nervosa. Horm. Metab. Res. 35, 537-540 (2003).

77. Spector, T. D., Hart, D. J. \& Doyle, D. V. Incidence and progression of osteoarthritis in women with unilateral knee disease in the general population: the effect of obesity. Ann. Rheum. Dis. 53, 565-568 (1994).

78. Tang, Q. et al. Association of osteoarthritis and circulating adiponectin levels: a systematic review and meta-analysis. Lipids Health Dis. 17, 189 (2018).

79. Doucette, C. R. et al. A high fat diet increases bone marrow adipose tissue (MAT) but does not alter trabecular or cortical bone mass in C57BL/6J mice. J. Cell. Physiol. 230, 2032-2037 (2015).

80. Fehrendt, $H$. et al. Negative influence of a long-term high-fat diet on murine bone architecture. Int. J. Endocrinol. 2014, 318924 (2014).

81. Gao, F., Lv, T. R., Zhou, J. C. \& Qin, X. D. Effects of obesity on the healing of bone fracture in mice. J. Orthop. Surg. Res. 13, 145 (2018).

82. Kim, S.-J., Ahn, J., Kim, H. K. \& Kim, J. H. Obese children experience more extremity fractures than nonobese children and are significantly more likely to die from traumatic injuries. Acta Paediatr. 105, 1152-1157 (2016).

83. Valerio, G. et al. Prevalence of overweight in children with bone fractures: a case control study. BMC Pediatr. 12, 166 (2012).

84. Lane, J. C. et al. Preschool obesity is associated with an increased risk of childhood fracture: a longitudinal cohort study of 466,997 children and up to 11 years of follow-up in Catalonia, Spain. J. Bone Miner. Res. 35, 1022-1030 (2020).

85. Anandacoomarasamy, A., Caterson, I., Sambrook, P., Fransen, M. \& March, L. The impact of obesity on the musculoskeletal system. Int. J. Obes. 32, 211-222 (2008).

86. Filkova, M. et al. Increased serum adiponectin levels in female patients with erosive compared with non-erosive osteoarthritis. Ann. Rheum. Dis. 68, 295-296 (2009).

87. Giambelli, R. et al. Adiponectin serum levels and disease severity in the STR/Ort mouse model of osteoarthritis. Osteoarthr. Cartil. 24, S85 (2016).

88. AlHW. Australia's dental generations: The National Survey of Adult Oral Health 2004-2006 (AlHW) (2004).

89. Zhang, L. et al. Adiponectin ameliorates experimental periodontitis in dietinduced obesity mice. PLoS One 9, e97824 (2014).

90. Kamio, N., Akifusa, S., Yamaguchi, N., Nonaka, K. \& Yamashita, Y. Antiinflammatory activity of a globular adiponectin function on RAW 264 cells stimulated by lipopolysaccharide from Aggregatibacter actinomycetemcomitans. FEMS Immunol. Med. Microbiol. 56, 241-247 (2009).

91. Šenolt, L., Pavelka, K., Housa, D. \& Haluzík, M. Increased adiponectin is negatively linked to the local inflammatory process in patients with rheumatoid arthritis. Cytokine 35, 247-252 (2006).

92. Ebina, K. et al. Serum adiponectin concentrations correlate with severity of rheumatoid arthritis evaluated by extent of joint destruction. Clin. Rheumatol. 28, 445-451 (2009)

93. Giles, J. T., Allison, M., Bingham, C. O., Scott, W. M. \& Bathon, J. M. Adiponectin is a mediator of the inverse association of adiposity with radiographic damage in rheumatoid arthritis. Arthritis Care Res. 61, 1248-1256 (2009).

94. Krumbholz, G. et al. Response of human rheumatoid arthritis osteoblasts and osteoclasts to adiponectin. Clin. Exp. Rheumatol. 35, 406-414 (2017).

95. Sudoł-Szopińska, l. et al. Significance of bone marrow edema in pathogenesis of rheumatoid arthritis. Pol. J. Radiol. 78, 57-63 (2013).

96. Shiratori, T. et al. IL-1 $\beta$ induces pathologically activated osteoclasts bearing extremely high levels of resorbing activity: a possible pathological subpopulation of osteoclasts, accompanied by suppressed expression of Kindlin-3 and Talin-1. J. Immunol. 200, 218-228 (2018).

97. Lee, Y. A. et al. Synergy between adiponectin and interleukin-1 $\beta$ on the expression of interleukin-6, interleukin-8, and cyclooxygenase- 2 in fibroblast-like synoviocytes. Exp. Mol. Med. 44, 440-447 (2012).

98. Qian, J. et al. Adiponectin aggravates bone erosion by promoting osteopontin production in synovial tissue of rheumatoid arthritis. Arthritis Res. Ther. 20, 26 (2018). 
99. Sun, X. et al. Adiponectin exacerbates collagen-induced arthritis via enhancing Th17 response and prompting RANKL expression. Sci. Rep. 5, 11296 (2015).

100. Lee, Y. A. et al. Potential therapeutic antibodies targeting specific adiponectin isoforms in rheumatoid arthritis. Arthritis Res. Ther. 20, 245 (2018).

101. Wu, D. et al. Adiponectin exerts a potent anti-arthritic effect and insulin resistance in collagen-induced arthritic rats. Int. J. Rheum. Dis. 21, 1496-1503 (2018).

102. Lee, S. W., Kim, J. H., Park, M. C., Park, Y. B. \& Lee, S. K. Adiponectin mitigates the severity of arthritis in mice with collagen-induced arthritis. Scand. J. Rheumatol. 37, 260-268 (2008).

103. Franchi, A. Epidemiology and classification of bone tumors. Clin. Cases Miner. Bone Metab. 9, 92-95 (2012).

104. Coleman, R. E. Metastatic bone disease: clinical features, pathophysiology and treatment strategies. Cancer Treat. Rev. 27, 165-176 (2001).

105. Märtson, A. et al. Transcriptome analysis of osteosarcoma identifies suppression of wnt pathway and up-regulation of adiponectin as potential biomarker. Genomics Discov. 1, 3 (2013).

106. Sapio, L. et al. AdipoRon affects cell cycle progression and inhibits proliferation in human osteosarcoma cells. J. Oncol. 2020, 1-12 (2020).

107. Cetin, K., Christiansen, C. F., Sværke, C., Jacobsen, J. B. \& Sørensen, H. T. Survival in patients with breast cancer with bone metastasis: a Danish population-based cohort study on the prognostic impact of initial stage of disease at breast cancer diagnosis and length of the bone metastasis-free interval. BMJ Open 5, e007702 (2015).

108. Dos Santos, E. et al. Adiponectin mediates an antiproliferative response in human MDA-MB 231 breast cancer cells. Oncol. Rep. 20, 971-977 (2008).

109. Kang, J. H. et al. Adiponectin induces growth arrest and apoptosis of MDA-MB231 breast cancer cell. Arch. Pharm. Res. 28, 1263-1269 (2005).

110. Libby, E. F. et al. Globular adiponectin enhances invasion in human breast cancer cells. Oncol. Lett. 11, 633-641 (2016).

111. Fowler, J. A. et al. Host-derived adiponectin is tumor-suppressive and a novel therapeutic target for multiple myeloma and the associated bone disease. Blood 118, 5872-5882 (2011).
112. Bacon, S. \& Crowley, R. Developments in rare bone diseases and mineral disorders. Ther. Adv. Chronic Dis. 9, 51-60 (2018).

113. Boraschi-Diaz, l. et al. Metabolic phenotype in the mouse model of osteogenesis imperfecta. J. Endocrinol. 234, 279-289 (2017).

114. Lacerda, D. R. et al. Osteopetrosis in obese female rats is site-specifically inhibited by physical training. Exp. Physiol. 100, 44-56 (2015).

115. Uckan, D. et al. Adipocyte differentiation defect in mesenchymal stromal cells of patients with malignant infantile osteopetrosis. Cytotherapy 11, 392-402 (2009).

116. Granero-Moltó, F. et al. Regenerative effects of transplanted mesenchymal stem cells in fracture healing. Stem Cells 27, 1887-1898 (2009).

117. Asiedu, K. O. et al. Bone marrow cell homing to sites of acute tibial fracture: ${ }^{89} \mathrm{Zr}$ oxine cell labeling with positron emission tomographic imaging in a mouse model. EJNMMI Res. 8, 109 (2018).

118. Walton, M. Degenerative joint disease in the mouse knee; histological observations. J. Pathol. 123, 109-122 (1977).

(i) Open Access This article is licensed under a Creative Commons Attribution 4.0 International License, which permits use, sharing, adaptation, distribution and reproduction in any medium or format, as long as you give appropriate credit to the original author(s) and the source, provide a link to the Creative Commons license, and indicate if changes were made. The images or other third party material in this article are included in the article's Creative Commons license, unless indicated otherwise in a credit line to the material. If material is not included in the article's Creative Commons license and your intended use is not permitted by statutory regulation or exceeds the permitted use, you will need to obtain permission directly from the copyright holder. To view a copy of this license, visit http://creativecommons. org/licenses/by/4.0/.

(c) The Author(s) 2021 